\title{
Danger of Laparoscopic Umbilical Port in Portal Hypertensive Cirrhotic Patient: A Case Report
}

\author{
Suppadech Tunruttanakul ${ }^{1}$, Kotchakorn Verasmith ${ }^{2}$
}

\begin{abstract}
Laparoscopic surgery has been proved to be safe and better option for Child-Pugh (CP) score class I and II cirrhotic patients. Various challenging laparoscopic surgeries have been applied to this group of patients. This case report was of an obese man, CP class I alcoholic cirrhotic patient with radiological evidence of portal hypertension, inflicted with cecal adenocarcinoma. Laparoscopic right hemicolectomy was planned. First camera port incision was made on infraumbilical position and injured to large paraumbilical collateral, which drained blood from the main portal vein. The patient was survived but suffered from postoperative ascites and postponing definite surgery. The preoperative computed tomography was reviewed and detailed of these collateral vessels. This report aims to raise awareness of this potential complication and reveal the imaging with discussion of avoiding options.

Keywords: Cirrhosis, Laparoscopic surgery, Paraumbilical collaterals, Portal hypertension.

World Journal of Laparoscopic Surgery (2019): 10.5005/jp-journals-10033-1371
\end{abstract}

\section{INTRODUCTION}

Liver cirrhosis has been a contraindication for laparoscopic cholecystectomy. ${ }^{1}$ However, currently, many high-level evidences have revealed that it is safe and maybe better than open surgery in terms of fewer complications, length of hospital stay, and recovery. ${ }^{2,3}$ Nevertheless, these safties are limited only on CP score class I and II cirrhotic patients. ${ }^{2,3}$ In the beginning, laparoscopic surgery in cirrhotic patients was mostly limited to cholecystectomies. With more developed in minimally invasive surgical equipment, the procedures have expanded to cover many more challenging surgeries such as gastrectomy, ${ }^{4}$ colorectal surgery, ${ }^{5}$ splenectomy, ${ }^{6}$ etc.

Most of the laparoscopic procedures begin with creating abdominal tunnel for a trocar for the laparoscopic camera, which is usually located around the umbilical area. Majority of studies included an umbilical port in the procedure. ${ }^{5,7-9}$ This case report aims to alert surgeons to aware of a potentially serious bleeding complication that can occur from creating an umbilical port in a cirrhotic patient with portal hypertension.

\section{Clinical Case Description}

A 66-year-old male, known-case alcoholic cirrhosis, came to the hospital with clinical constipation and occasional abdominal pain. Colonoscopy was later utilized and detected fungating mass located in the cecal area. Pathologic examination later confirmed adenocarcinoma. Computed tomography was then organized and revealed circumferential, enhancing mass at the cecum. Morphologically liver cirrhosis and portal hypertension (seen collateral vessels) without ascites were also reported in the study. There was no evidence of distant metastasis, and the patient was fit with had only cirrhosis as his underlying disease. Regarding body mass index classification, he was categorized as obesity with body mass index 32.4 (bodyweight $83 \mathrm{~kg}$ and height $160 \mathrm{~cm}$ ). His preoperative blood test results were as followings.

Complete blood count: hemoglobin $8.5 \mathrm{~g} / \mathrm{dL}$, white blood counts $4,230 / \mu \mathrm{L}$, and platelet counts $1,13,000 / \mu \mathrm{L}$.

\begin{abstract}
'Department of Surgery, Sawanpracharak Hospital, Nakhon Sawan, Thailand

${ }^{2}$ Department of Radiology, Sawanpracharak Hospital, Nakhon Sawan,
\end{abstract} Thailand

Corresponding Author: Suppadech Tunruttanakul, Department of Surgery, Sawanpracharak Hospital, Nakhon Sawan, Thailand, Phone: +66 897590770, e-mail: sdtaaa@yahoo.com

How to cite this article: Tunruttanakul S, Verasmith K. Danger of Laparoscopic Umbilical Port in Portal Hypertensive Cirrhotic Patient: A Case Report. World J Lap Surg 2019;12(2):83-85.

Source of support: Nil

Conflict of interest: None

Liver function test: total protein $8.0 \mathrm{~g} / \mathrm{dL}$, albumin $3.6 \mathrm{~g} / \mathrm{dL}$, globulin $4.4 \mathrm{~g} / \mathrm{dL}$, aspartate aminotransferase $32 \mathrm{U} / \mathrm{L}$, alanine aminotransferase $17 \mathrm{U} / \mathrm{L}$, alkaline phosphatase $69 \mathrm{U} / \mathrm{L}$, total bilirubin $1.02 \mathrm{mg} / \mathrm{dL}$, and direct bilirubin $0.53 \mathrm{mg} / \mathrm{dL}$.

Coagulogram: prothrombin time (PT) 14.8 second with international normalization ratio (INR) 1.21, partial thromboplastin time (PTT) 26.0 with ratio 0.98 .

Blood urea nitrogen $8 \mathrm{mg} / \mathrm{dL}$ and creatinine $1.09 \mathrm{mg} / \mathrm{dL}$ (g = gram, $\mathrm{dL}=$ deciliter, $\mu \mathrm{L}=$ microliter, $\mathrm{U} / \mathrm{L}=$ international unit per liter and $\mathrm{mg}=$ milligram).

According to the patient's blood tests, most of the results were normal except slight thrombocytopenia, which can reflect having portal hypertension. Child-Pugh score was calculated, and the score was five (no ascites and hepatic encephalopathy), which categorized the patient as CP class I liver cirrhosis.

It can be summarized that the patient was inflicted resectable cecal cancer with CP class I alcoholic liver cirrhosis with portal hypertension. Surgical treatment was then planned laparoscopically.

Preoperatively, only some packed red cell was prepared, and prophylactic antibiotics were given. General anesthesia with some monitoring was applied without any concern. Umbilical incision was made on infraumbilical location, around one centimeter $(\mathrm{cm})$ in length with open technique under direct vision. After peritoneum 

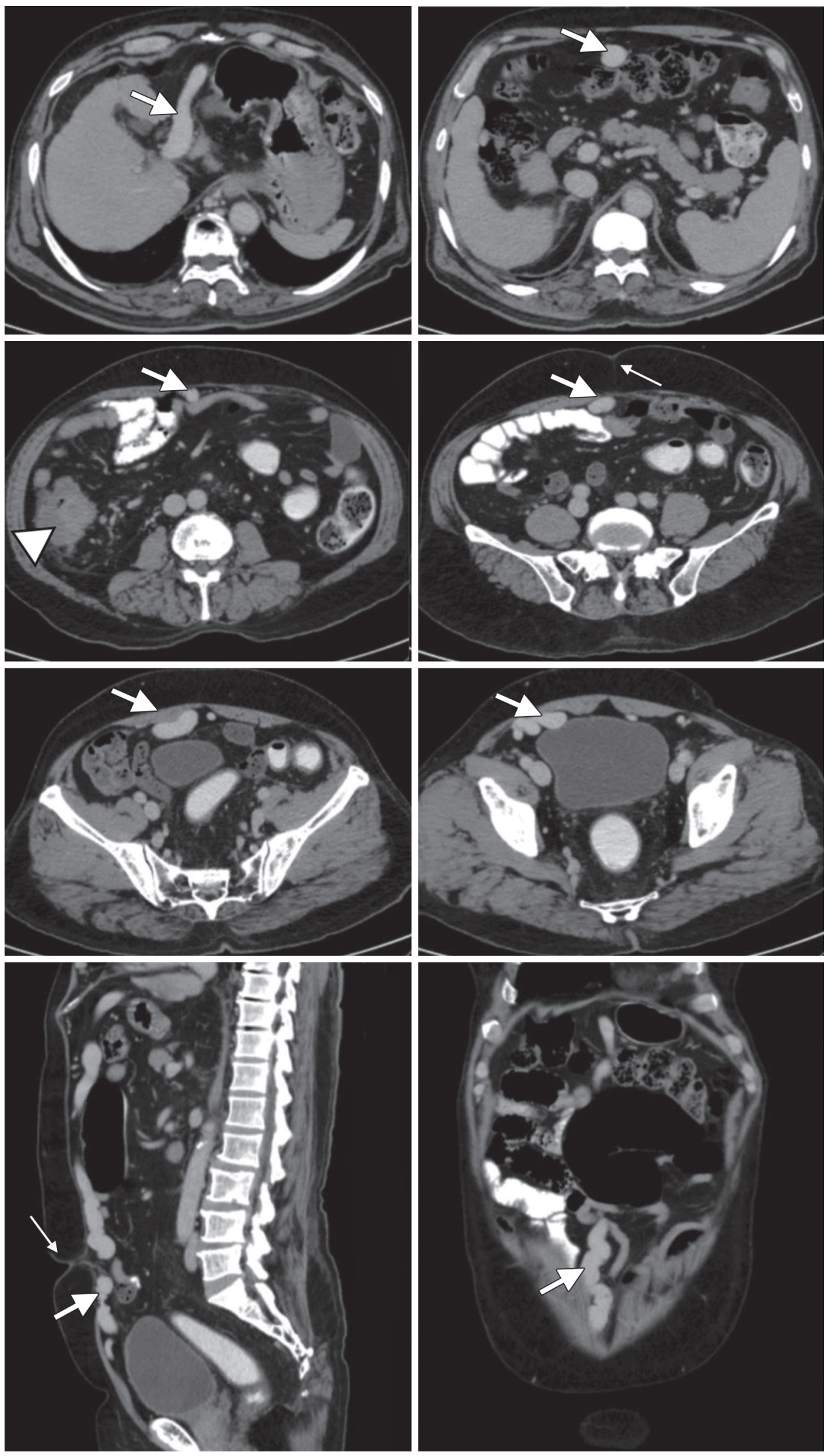

Fig. 1:The patient's computed tomography shown: Atrophic change of liver with nodular surface suggests cirrhosis. Dilated tortuous recanalized paraumbilical vein along midline of anterior abdomen (thick arrow), draining from left portal vein into bilateral inferior epigastric vessels. Tumor (arrow head) and umbilicus (thin arrow) were also demonstrated. Esophageal varices are also noted 
entered, a large amount of blood was gushed out. Stop bleeding was attempted through the $1 \mathrm{~cm}$ wound, but was unsuccessful due to small incision, blood rapidly obscuring surgical field and patient's thick abdominal wall. The incision was then extended to around $5 \mathrm{~cm}$, the bleeding vessel was identified as around $1.2 \mathrm{~cm}$ vein just above the layer of peritoneum and then controlled with suture-ligation. Patient's conditions at that time were unstable with hypotension, and volume of blood loss was around one liter. The procedure was then terminated, and the patient was transferred to be resuscitated in the intensive care unit. Postoperatively, the patient has gradually improved with medical controlled ascites. The second operation was planned after the patient has recovered.

Preoperative computed tomography was later reviewed (Fig. 1) and shown the large collateral vessel beneath the anterior abdominal wall, which ran from the hilar area of the liver through the falciform ligament to anterior abdominal wall, ran down to locate under the umbilicus. Size of the vessel at the injured location was around $1.5 \mathrm{~cm}$.

\section{Discussion}

Laparoscopic procedures were proved to be safe and beneficial in cirrhosis CP class I and II patients with less blood loss, shorter hospital stay, and earlier recovery. ${ }^{2,3}$ More challenging laparoscopic procedures were also utilized in these patients with acceptable outcomes. ${ }^{4-6}$ Most of the literature didn't report regarding portal hypertensive status. However, laparoscopic splenectomy, which is indicated in hypersplenism as the result of portal hypertension, was reflected in the application of laparoscopic surgery in these patients. ${ }^{6}$ Although appealing outcome, compared to noncirrhotic studies, the morbidity of the procedures was still higher. ${ }^{10}$

Caution in placing the umbilical port was recommended by Earl TM and Chapman WC in textbook of hepatobiliary surgery. ${ }^{11}$ To avoid collateral vessel, there was also a recommendation to choose an infraumbilical incision rather than a supraumbilical location. ${ }^{12}$ Our case report revealed that even infraumbilical incision might not be able to avoid anterior abdominal collateral vessels. The incidence of paraumbilical vein and abdominal wall veins collaterals, which drain into the superior or inferior epigastric veins, was around $43 \%$ in portal hypertensive patients. ${ }^{13}$ Even though, to our knowledge, the subset incidence of these collaterals, which drain into inferior epigastric veins that cause risk of injury from infraumbilical incision, is still unknown. The collateral vessel diameter can be very large, such as our case, and inflicts massive rapid loss of blood. In order to prevent air leakage around laparoscopic port during intra-abdominal gas inflation, surgeons trend to create as much small incision as possible. However, in the unexpected bleeding event, this small incision can prevent adequate visualization and causes delaying hemostatic control, especially in the thick abdominal wall. Volume of blood gushing worsens the aforementioned situation by obscuring an operative field. Preventive measures should be the best way for this occurrence that would be:

- Place the other ports first and place the umbilical port under direct vision. ${ }^{11}$

- Completely avoid the midline of umbilical area. ${ }^{14}$
- Reviewing of preoperative imaging to search for a collateral vessel such as our case. However, CT scan was not routinely utilized especially in laparoscopic cholecystectomy cases.

\section{Conclusion}

Although various laparoscopic surgeries are recently supported in CP class I and II cirrhotic patients. However, these groups of patients still possess a higher chance of procedure-related complication. Collateral vessels secondary to portal hypertension can cause serious major bleeding from creating an umbilical port that should be aware.

\section{References}

1. Yerdel MA, Tsuge H, Mimura H, et al. Laparoscopic cholecystectomy in cirrhotic patients: expanding indications. Surg Laparosc Endosc 1993;3(3):180-183.

2. de Goede B, Klitsie PJ, Hagen SM, et al. Meta-analysis of laparoscopic versus open cholecystectomy for patients with liver cirrhosis and symptomatic cholecystolithiasis. Br J Surg 2013;100(2):209-216. DOI: 10.1002/bjs.8911.

3. Laurence JM, Tran PD, Richardson AJ, et al. Laparoscopic or open cholecystectomy in cirrhosis: a systematic review of outcomes and meta-analysis of randomized trials. HPB 2012;14(3):153-161. DOI: 10.1111/j.1477-2574.2011.00425.x.

4. Kim DJ, Park CH, Kim W, et al. Safety of laparoscopic radical gastrectomy in gastric cancer patients with liver cirrhosis. Surg Endosc 2017;31(10):3898-3904. DOI: 10.1007/s00464-017-5420-5.

5. Zhou S, Zhu H, Li Z, et al. Safety of laparoscopic resection for colorectal cancer in patients with liver cirrhosis: a retrospective cohort study. Int J Surg 2018;55:110-116. DOI: 10.1016/j.ijsu.2018.05.730.

6. Zhan XL, Ji Y, Wang YD. Laparoscopic splenectomy for hypersplenism secondary to liver cirrhosis and portal hypertension. World J Gastroenterol 2014;20(19):5794-5800. DOI: 10.3748/wjg.v20.i19.5794.

7. El-Awadi S, El-Nakeeb A, Youssef T, et al. Laparoscopic versus open cholecystectomy in cirrhotic patients: a prospective randomized study. Int J Surg 2009;7(1):66-69. DOI: 10.1016/j.ijsu.2008.10.013.

8. Hamad MA, Thabet M, Badawy A, et al. Laparoscopic versus open cholecystectomy in patients with liver cirrhosis: a prospective, randomized study. J Laparoendosc Adv Surg Tech A 2010;20(5): 405-409. DOI: 10.1089/lap.2009.0476.

9. Ji W, Li LT, Wang ZM, et al. A randomized controlled trial of laparoscopic versus open cholecystectomy in patients with cirrhotic portal hypertension. World J Gastroenterol 2005;11(16):2513-2517. DOI: 10.3748/wjg.v11.i16.2513.

10. Puggioni A, Wong LL. A metaanalysis of laparoscopic cholecystectomy in patients with cirrhosis. J Am Coll Surg 2003;197(6):921-926. DOI: 10.1016/j.jamcollsurg.2003.08.011.

11. Earl TM, Chapman WC. Nonhepatic surgery in the cirrhotic patient. In: Jarnagin W, ed. Blumgart's surgery of the liver, biliary tract and pancreas. 2, 6th ed., Elsevier; 2017. pp. 1161-1167.

12. Nguyen KT, Kitisin K, Steel J, et al. Cirrhosis is not a contraindication to laparoscopic cholecystectomy: results and practical recommendations. HPB (Oxford) 2011;13(3):192-197. DOI: 10.1111/j.1477-2574.2010.00270.x.

13. Moubarak E, Bouvier A, Boursier J, et al. Portosystemic collateral vessels in liver cirrhosis: a three-dimensional MDCT pictorial review. Abdom Imaging 2012;37(5):746-766. DOI: 10.1007/s00261-011-9811-0.

14. Palanisamy S, Sabnis SC, Patel ND, et al. Laparoscopic major hepatectomy-technique and outcomes. J Gastrointest Surg 2015;19(12):2215-2222. DOI: 10.1007/s11605-015-2933-x. 